\title{
Formas de autoorientación de la sociedad
}

\author{
Forms of Societal Self-Steering
}

\section{Helmut Willke}

Departamento de Gobernanza Global, Universidad Zeppelin, Alemania

\section{RESUMEN}

El artículo exhibe la paradójica relación entre diferenciación, interdependencia y clausura operativa de sistemas sociales en la sociedad moderna, y expone cómo esa paradoja aumenta las expectativas de intervención política, por un lado, y las de auto-orientación de sistemas autónomos, por otro. Puesto que la jerarquía no es una opción como principio general de orientación social, surge la pregunta acerca de cómo es posible aún construir un orden social que reconcilie autonomía e interdependencia. El artículo sostiene que existen tres mecanismos complejos que pueden estar a la altura de este desafío: la reflexividad como civilización de la auto-referencia, la intervención contextual como civilización del poder, y los discursos sistémicos como mejoramiento de la conectividad informacional. Con varias ilustraciones empíricas, el artículo ofrece una alternativa de conducción social entre la jerarquía y el escenario arrégleselas como pueda.

PALABRAS CLAVE: Sistemas sociales; Reflexividad; Intervención contextual; Coordinación social; Autoorientación social; Sistemas de deliberación

\section{ABSTRACT}

The article uncovers the paradoxical relation between differentiation, interdependence and operational closure of social systems in modern society, and how this paradox increases the expectations for political intervention, on the one hand, and for societal self-steering of autonomous systems, on the other. Since hierarchy is not an option as an overarching principle of societal guidance, the question arises as to how is still possible to build a social order that reconciles autonomy and interdependence. The article argues that three complex mechanisms rise to this challenge: reflexivity as civilization of self-reference, contextual intervention as civilization of power, and systemic discourses as improvement of informational connectivity. With several empirical illustrations, the article offers an alternative for societal guidance between hierarchical control and the muddling-through scenario.

KEYWORDS: Social systems; Reflexivity; Contextual intervention; Societal coordination; Societal self-steering; Deliberation systems

\footnotetext{
REVISTA MAD - REVISTA DEL MAGÍSTER EN ANÁLISIS SISTÉMICO APLICADO A LA SOCIEDAD ISSN 0718-0527

Facultad de Ciencias Sociales, Departamento de Antropología.

Universidad de Chile

www.revistamad.uchile.cl
}

DOI: http://dx.doi.org/10.5354/0718-0527.2016.40608 


\section{INTRODUCCIÓN ${ }^{1}$}

Todavía aparece a muchos observadores como incomprensible o temerario hablar de autoorganización de una sociedad. Aún está vigente la representación de que el desarrollo de las sociedades está determinado por un plan sagrado, por leyes de la naturaleza o de la historia, por un destino ciego, por la casualidad o por individuos carismáticos. Es probablemente imposible refutar convencimientos de este tipo, precisamente porque las sociedades no funcionan como máquinas triviales y su modo de operación, por lo mismo, no puede ser resumido en una simple ley.

En efecto, se puede ver que las sociedades, después de su entrada en los nuevos tiempos (ver aquí Koselleck 1979: 300ss; Polanyi 1978), es decir, con el paso del feudalismo a una diferenciación funcional, industrialización y politización que se han propagado paulatinamente, se deshacen crecientemente de las representaciones tradicionales del orden y -bajo la influencia de pensadores como Bodin, Hobbes, Rousseau, Locke, Montesquieu, los federalistas americanos, Kant, Hegel y finalmente Marxdescubren la realizabilidad de su mundo. En lo que sigue, se profundizará desde dos diferentes puntos de vista. Por un lado, se examinarán (a través de los conceptos de reflexión, intervención contextual y discurso sistémico) algunos mecanismos centrales de la autoorientación de la sociedad, para que así se esclarezcan las dificultades y posibilidades de esta autoorientación. ${ }^{2}$ Por otro lado, se tratará nuevamente la pregunta por la posibilidad y riesgo del orden social para el caso de sistemas desarrollados y altamente complejos.

La representación del orden político encarnada en el Estado, junto con la positivización del derecho, fueron condiciones esenciales para que se pudieran disolver los vínculos con los modelos de orden social tradicional, en general, religiosamente motivados $\mathrm{y}$, en un proceso

\footnotetext{
${ }^{1}$ Traducción de Aldo Mascareño, Director Núcleo Milenio Modelos de Crisis (NS130017), Escuela de Gobierno, Universidad Adolfo Ibáñez (con la colaboración de Maureen Neckelmann). Texto original: Kapitel 4. Formen gesellschaftlicher Selbststeuerung (111-140), en Willke, H. (1993): Systemtheorie entwickelter Gesellschaften. Dynamik und Riskanz moderner gesellschaftlicher Selbstorganisation. München: Juventa Verlag.

${ }^{2}$ En su interpretación sistémica, la palabra alemana Steuerung puede ser traducida como orientación o conducción. En esta traducción, y luego de su análisis con el autor del texto, he privilegiado el concepto de orientación. El término regulación ha sido desechado básicamente por dos razones: en primer lugar, éste dispone de un vocablo preciso en alemán: la palabra de origen latino Regulierung, a la que Willke asigna un sentido distinto e incluso contrapuesto a Steuerung. En segundo lugar, el debate en torno a la regulación tiene ya una larga tradición al interior de la teoría económica. En apoyo a esta elección puede citarse al propio Willke, quien en inglés utiliza la palabra guidance para significar Steuerung, desechando incluso el término steering, en apariencia más cercano. (N. del t.)
} 
histórico gradual de secularización, ser sustituidos por proyectos de orden mundial. Con esto, el orden social se define -de cualquier modo y a lo menos- por decisiones voluntaristas de legisladores, los que ya no se orientan primariamente hacia la religión o la tradición, sino por objetivos políticos que resultan de un proceso político de coordinación (estructurado en sí mismo).

Por eso, no es sorprendente que hasta ahora la modernidad se haya comprendido primariamente en relación con el grado y la calidad de la configuración política del orden social, incluyendo la configuración política del orden económico. Con esto -como ya se ha explicado brevemente más arriba- se le atribuye al sistema político el rol de instancia central, es decir, de cima jerárquica de la sociedad. Es según esta representación de las decisiones políticas que se estructura la sociedad, se determina la forma de su ordenamiento, se delimita el campo de posibilidad de lo realizable y de lo que se debe hacer, y con eso se define la realidad social.

Existen de hecho suficientes justificaciones para la plausibilidad de este modo de mirar las cosas. Con la formación del Estado social y de bienestar, el Estado (como sustancia, referente y autodescripción del sistema político) emerge más poderoso e imprescindible que nunca. El raudal de leyes es incalculable, la juridificación avanza hasta el último rincón del mundo de la vida, por las manos públicas y ministerios corre según estimaciones- $40 \%$ a $50 \%$ del producto social bruto; nuevas tecnologías de información, comunicación, vigilancia e impuestos han acercado al presente "la jaula de hierro del futuro" sobre el cual advertía Max Weber (1972: 835s).

Si se dirige la mirada al Estado (como expresión del modo de trabajo del sistema político), aparecen intromisiones y trámites estatales, pero por otro lado también aparece más fuertemente que nunca el clamor por intervención política y asistencia estatal. La omnipresencia de la burocracia estatal se generaliza: sin el Estado nada avanza. Paradójicamente se demuestra lo contrario cuando la mirada se dirige hacia la sociedad y sus subsistemas. Los protagonistas de la confrontación político-administrativa no son individuos, sino grupos organizados. El paso de las grandes asociaciones, organizaciones, sindicatos, profesiones, grupos de interés y corporaciones a 'subordinados superpoderosos' indica una transformación muy profunda en las formas y mecanismos de orientación y control social: sin actores sociales organizados nada avanza. La sociedad ya no consiste, desde esta perspectiva, en individuos mantenidos en conjunto por un gobierno de orden superior; ella consiste 
más bien en una configuración de gobiernos privados y públicos con interrelaciones complejamente entrelazadas (Bobbio 1984; Unger 1976; Willke 1983).

Estas dos impresiones opuestas se complementan cuando se toma en cuenta la dialéctica de exclusión (especialización) e inclusión en sociedades desarrolladas. Los sistemas funcionales como la política, economía, ciencia, educación, etc., se especializan y se vuelven competentes exclusivamente para un aspecto específico de la reproducción social. En este sentido, 'excluyen' a todos los otros ámbitos del cumplimiento de esta función específica. Así, por ejemplo, el sistema científico es competente para la verdad, pero no la política, la religión o la economía. Para las decisiones sobre el ejercicio de poder público legítimo es competente el sistema político, no el sistema educativo, el sistema de salud o la economía, etc. Pero, por otro lado, todos los eventos sociales pueden ser potencialmente relevantes para un determinado sistema funcional; su 'campo de interés' y horizonte de percepción se extienden por toda la sociedad y abarcan potencialmente todo (inclusión). Por ejemplo, el descubrimiento científico más descabellado puede ser económicamente relevante, un desarrollo en el sistema educativo puede provocar oleaje político o una nueva tecnología puede ser de gran significado para el sistema de salud. Esto obliga a los sistemas funcionales a leer continuamente de una manera especial todo el campo de acontecimientos posibles, buscando una relevancia específica. Esto puede conducir a que se produzcan reacciones sorpresivas ante acontecimientos 'en sí insignificantes, pues el sistema funcional no puede resistirse a eventos que son relevantes en su lenguaje y según sus criterios de selección: "La economía, por ejemplo, está entregada sin remedio a los descubrimientos científicos y a las invenciones técnicas en tanto éstas se dejen valorar económicamente. Lo mismo vale (...) para la relación de la política y el derecho, para la relación de la ciencia y la medicina y para muchos otros casos" (Luhmann 1986: 221s). Evidentemente, esta dialéctica de inclusión y exclusión conduce simultáneamente a un aumento de la especialización fáctica y a una responsabilidad total, a una indiferencia generalizada y a un interés hipotético por todo. Talcott Parsons, en especial, usa el concepto de inclusión de otra manera y lo relaciona con personas: a través de la inclusión se vuelven significativos una y otra vez procesos funcionales específicos para todos los miembros de la sociedad; por ejemplo: se amplía el derecho a voto a cada vez más grupos de personas, un mayor número de personas pasan a formar parte del proceso 
educativo, y el comercio en la economía se abre, en principio, a todos los ciudadanos (ver en este punto Stichweh 1988).

Esta dialéctica de exclusión e inclusión ha superado a la que por mucho tiempo fue una controversia central: el primado del mercado capitalista, por un lado, y el primado de la política estatal, por el otro. El desarrollo social ha creado hasta ahora nuevas exigencias para la unidad social y para el problema de la orientación de estas sociedades, mientras que la pregunta por el primado de sólo un sistema parcial tiene cada vez menos sentido. Ya no es una interrogante necesaria si la economía o la política 'determinan' una sociedad desarrollada.

Estos sistemas cubren problemas especialmente complejos, como por ejemplo la planificación científica y tecnológica, la política de seguridad, el uso del espacio, las políticas de salud y ambientales o la formación del mercado europeo hasta 1992. En todos estos ejemplos, las valoraciones económicas, políticas, científicas y de otro tipo se han mezclado sin posibilidad de separar beneficios y costos privados o colectivos. Estas valoraciones y cálculos varían según el horizonte temporal en juego y según la calidad del conocimiento disponible y empleado. Ellos cambian según los problemas resultantes y según las contradicciones y conflictos venideros; están mutuamente entrelazados, y los progresos u omisiones de un ámbito de problemas afectan retroactivamente a todos los demás.

La verdadera dificultad del análisis de sociedades complejas y de la búsqueda de los principios de su autoorganización descansa en la relación paradójica de un aumento simultáneo de la diferenciación e interdependencia de los ámbitos funcionales de la sociedad, y esto en vistas a reflexionar sobre la pregunta por la unidad y orden de la sociedad en su conjunto.

Mientras más claramente sujetos están los procesos de evolución de sistemas diferenciados -a través de la especificación e internalización de los mecanismos de evolución de variación, selección y estabilización al bozal de los criterios internos de sistemas parciales, más precaria se vuelve la conexión de las partes de una sociedad; más independientes, autorreferentes y clausurados se tornan los modos de operación de las partes y menos se dejan fijar los ámbitos funcionales por un ordenamiento general. Así se desarrollan, en primera línea, procesos -en el sistema educativo, de salud o científico- orientados hacia la dinámica y regulación propias de estos sistemas, los que no pueden ser simplemente orientados, ni de ningún modo determinados, por la política o la economía. Por el contrario, los insistentes alegatos de la política sobre el déficit de 
implementación (véase Mayntz 1983), o de la economía sobre las dificultades de coordinación con el sistema de educación (véase Eichmann 1989), o del sistema científico sobre el déficit de coordinación con la política y la economía (véase Foemer 1981), prueban que la misma coevolución y coordinación es difícil ahí donde es deseada por ambas partes afectadas.

Esto muestra un dilema profundo de las sociedades modernas: dos principios evolutivos se transforman de manera creciente en un problema. Por un lado, el principio de la diferenciación funcional según el cual, bajo una creciente tendencia a la especialización y estrechamiento temático de las funciones, se intensifican las interdependencias entre los sistemas funcionales, pues cada sistema social parcial sólo puede generar una unidad capaz de constituirse como función y de evolucionar -incluso la sociedad lo hace- en relación mutua con todos los otros sistemas parciales. Por otro lado, está el principio de la clausura operacional, según el cual los subsistemas intensifican su independencia por medio de una creciente autonomía y recursividad de su modo de operación porque con la autorreferencia y la clausura operacional, los sistemas funcionales se transforman en ámbitos 'dirigidos internamente', los que sólo se dejan impresionar de forma muy selectiva por los acontecimientos del entorno.

Un buen y preciso indicador empírico para observar el dilema de dependencia y autonomía creciente es el hecho de que los sistemas parciales, como la economía, la tecnología, la ciencia, la milicia o el derecho, producen externalidades negativas masivas tanto para su entorno social como también para otros sistemas parciales o para el mundo de la vida en su conjunto. Se amenazan mutuamente y producen riesgos colectivos, los que sin lugar a dudas se pueden volver sobre ellos mismos. No obstante, es extraordinariamente difícil lograr una compensación interna o incluso sólo una sensibilidad para el significado de estas externalidades a causa de la alta indiferencia frente a los acontecimientos del entorno. Tal sensibilidad demanda las exigentes capacidades de reflexión, intervención contextual y de discurso sistémico, las cuales serán el objeto de los siguientes párrafos (para las dificultades de coordinación Luhmann 1986; Teubner 1982; Willke 1987b).

La racionalidad propia y la eficiencia altamente cultivadas de los sistemas parciales ponen frente al todo sólo un fragmento de una idea de Estado que no se deja ni revivir por una retórica jurídica o filosófico-social, ni tampoco ha podido hasta ahora ser sustituida por una política especializada en la administración de los problemas del pasado. En vez de 
esto, se observa actualmente una alta relevancia de las partes, de las racionalidades y perspectivas parciales y -correspondientemente con esto- profundas dificultades en la posibilidad de representabilidad y de dotar de sentido al todo: a la unidad de las sociedades desarrolladas.

Aún más grave es que la inasible problemática del juego mutuo de los ámbitos funcionales de las sociedades altamente complejas, lleva a representaciones paradojales y riesgosas sobre las posibles soluciones del problema de identidad de estas sociedades. Todavía existen súplicas de viejas fórmulas identitarias como dios, la naturaleza, la historia o el Estado -y el hecho de que, en este siglo, bajo el estandarte de estas fórmulas, los túneles de roedores bajo tierra se hayan transformado en catástrofes sociales, debería advertir sobre la subestimación de la potencialidad regresiva de las 'formulaciones simples'. No se puede dejar de ver entretanto que para las sociedades desarrolladas los conceptos capitalismo y socialismo se han retrotraído a esas fórmulas simples, las que ya no designan realidades, sino que sólo la falsean.

Lo que está en el debate en vista de la problemática y riesgo observables en las sociedades modernas es no menos que la pregunta por el orden de estas sociedades, esto es, la pregunta por la arquitectura de su complejidad. Como sea que esta pregunta se haya respondido en el último siglo o cuán diferenciadas hayan sido las respuestas particulares, siempre pareció indudable que este orden debería haber sido jerárquico. Orden sin estructura jerárquica parece impensable. Lo mismo sucedía cuando con el paso a los nuevos tiempos se registra y tematiza -en el topos de la división social del trabajo- el primado de la diferenciación funcional de las sociedades modernas de la época (véase sobre todo Smith 1974 [1776]), cuando se desarrollan crecientemente debates y discusiones sobre qué grupo o sistema parcial debiese dar forma a la cima jerárquica de la sociedad (ver por ejemplo la idea de Saint-Simon de un gobierno de empresarios y científicos). Pero que una cima jerárquica sea indispensable es una suposición básica que poseen todas las tendencias desde Hegel pasando por Marx hasta Weber -con la significativa excepción de los anarquistas, o sea, aquellos que rechazan el orden como tal.

La teoría del Estado y la filosofía política sostienen gustosamente este pensamiento profundamente arraigado en categorías jerárquicas, también en sus formas desprejuiciadas. Incluso para sociedades democráticas donde 'el pueblo' figura como soberano abstracto, parece imposible dejar intacto el primado jerárquico del Estado en la organización concreta de la vida social. Que el Estado sea 
obligatoriamente quien al fin y al cabo deba decidir, hace que esta autoilusión de una profesión entera de científicos del Estado y de la sociedad sólo se deje comprender absolutamente sobre el trasfondo de un espanto total, en torno a la posibilidad de pensar un orden social sin el corsé de la jerarquía.

Existen naturalmente buenas razones para el predominio de la jerarquía como forma de orden. Solamente con ella fue posible el paso histórico desde sociedades multicéntricas segmentariamente diferenciadas (arcaicas) hacia sociedades estratificadas de cultura desarrollada, en las cuales los diferentes estamentos encajan en un orden jerárquico con una cima claramente reconocible -por ejemplo, en el sistema de castas de la India con los brahmanes en la cima. La ventaja evolutiva de esta forma de orden se produce por su alta compatibilidad con la inseguridad y el cambio, por su alto rendimiento en el aumento de la complejidad social frente una forma social diferenciada segmentariamente. Luego, a más tardar desde el temprano medioevo, la iglesia católica desarrolló siempre una pronunciada forma de organización jerárquica, y también las tempranas formaciones estatales en Inglaterra y después en Francia con la dominación del centro sobre a la periferia, y otras jerarquías como aquella entre la casa del rey y la nobleza restante, se puede por lo menos reconocer que el principio de orden jerárquico ofrece claras ventajas de desarrollo frente a un orden policéntrico segmentario. Este permite una descomposición de los logros sociales y a través de esto una acumulación y concentración de los recursos culturales, materiales y tecnológicos repartidos entre los distintos estamentos.

Una explicación general de la superioridad de la jerarquía como arquitectura de la complejidad fue entregada por Herbert Simon. En efecto, su idea central de la construcción 'modular' de los sistemas complejos, o sea, de la descomposición de los sistemas complejos en relaciones escalonables sistema-subsistema, señala claramente una jerarquía en un sentido convencional. Efectivamente, él postula incluso que, en los sistemas complejos, en el nivel de las relaciones de los subsistemas, no existen relaciones de subordinación (Simon 1978: 97).

De esta forma, se evidencia una importante diferencia entre un sistema de estructura primaria estratificada y uno de estructura primaria funcional: en un orden de estratos, las relaciones jerárquicas supraordinadas y subordinadas van desde arriba hacia abajo. En las sociedades funcionalmente diferenciadas de la modernidad temprana, por el contrario, el Estado permanece claramente en la posición de cima 
jerárquica. Pero debajo de ella ya no se determinan relaciones subordinadas - por ejemplo, entre el sistema educativo, la ciencia, la religión, la tecnología, el arte o el sistema de salud. Con la excepción del Estado, es evidente para los restantes sistemas parciales de la sociedad en continuo proceso de diferenciación, que en la red de sus independencias (operativas) y sus dependencias recíprocas (funcionales) son principalmente del mismo nivel, y que cualquier supuesto de prioridad es contradictorio porque va contra el principio de la diferenciación funcional.

Con el paso al primado de una diferenciación funcional como principio estructural de las sociedades modernas, se suprime una de las justificaciones de la jerarquía derivada del modo de operación del sistema. Para ser exactos, se debe formular de modo más fuerte y decir que un sistema complejo, diferenciado funcionalmente, debe formar un orden interno independiente, el cual contradiga claramente el principio de ordenamiento jerárquico, pues ¿qué parte de plexo de relaciones interdependientes debiera exigir una ventaja sobre las otras? Si todos los logros individuales y las funciones de los sistemas parciales especializados son imprescindibles para la mantención y la autorreproducción de una sociedad, ¿qué partes deberían estar entonces supraordinadas o subordinadas?

En un planteamiento muy análogo -a saber: en la investigación del cerebro humano como un sistema complejo- Warren McCulloch extrajo una consecuencia parecida en contra de la contundente tradición de pensamiento que defiende la constitución jerárquica del cerebro. Él postula que el cerebro, debido a su alta complejidad, no puede ser ya entendido como estructurado jerárquicamente. En vez de esto, habla de "heterarquía" (McCulloch 1965: 40ss) y de las redes del campo neuronal. Un paralelo importante se encuentra también en la discusión actual sobre los distintos planteamientos para la investigación de sistemas de inteligencia artificial: mientras los 'tradicionalistas' parten de una construcción programática jerárquica y de una unidad de procesamiento central del tipo 'máquina-von-Neumann' (computadores convencionales), los 'conexionistas' piensan en circuitos comunes paralelos de muchos computadores descentralizados (ver Daedalus 1988; también Peat 1988: 314ss).

Heinz von Foerster (1984: 8) conceptualizó y precisó la idea de la heterarquía de los sistemas altamente complejos al afirmar que ésta puede entenderse como un 'principio del direccionamiento potencial': en una red compleja, la autoridad de direccionamiento u orientación del todo 
recaería en los sistemas funcionales, los cuales disponen -en una situación dada- de la información óptima. Esto tiene en cuenta la comprensión de que en los sistemas funcionales diferenciados e interdependientes ningún subsistema puede exigir para sí a priori el primado o la competencia para la orientación.

Sobre este tema aparece en la discusión, con el término 'información óptima', un aspecto que puede explicar por qué (con el sistema político) el Estado se ha podido sostener tan larga y exitosamente como cima jerárquica de una formación social, en la cual una estructura jerárquica de las relaciones entre sistemas funcionales ya se había vuelto anacrónica. Al sistema político le ha sido y le es atribuida la capacidad de reunir y también de implementar -en la forma de programas de intervención jurídicos y fiscales- información exitosa para el ordenamiento y orientación de la sociedad. Es precisamente la paulatina pero irreversible disolución de esta ficción, la que hace imposible también para la teoría del Estado y la teoría social ocuparse del desencantamiento del Estado (Willke 1983, 1986a) y de las consecuencias del fin de la jerarquía.

Una mirada genuina sobre las sociedades desarrolladas occidentales muestra también con toda claridad aquellos cambios que señalan el agotamiento de la jerarquía como principio de ordenamiento de estas sociedades. Por un lado, es evidente que, contrariamente a una comprensión individualista de la sociedad, no son individuos los que dan forma al proceso político en sus consecuencias decisivas, sino los grupos organizados y los imperativos funcionales de los sistemas sociales parciales. Los actores organizados y colectivos consiguieron las oportunidades de participación, de decisión compartida y de orientación, porque ellos son insustituibles en aquellas decisiones que marcan las problemáticas específicas y los riesgos de las sociedades desarrolladas. Son insustituibles desde dos puntos de vista: primero, por su capacidad de generación y valoración de informaciones especializadas altamente específicas, y segundo, por su capacidad de implementar y llevar a cabo en sus ámbitos respectivos, representaciones del orden y estrategias de orientación -y esto significa sobre todo producir buena disposición (aceptación) en sus miembros, como también implementar los procedimientos exitosos y generar estructuras.

Así, por ejemplo, decisiones en el ámbito de la orientación del sistema de salud, la política científica y tecnológica, el fomento a la economía, la reforma al sistema de formación profesional, la política 
energética, la utilización pacífica o militar del espacio, el combate a las drogas, la reforma psiquiátrica, etc., están mucho más allá de la competencia burocrática tradicional de la política organizada estatalmente. Cuando, no obstante, el tratamiento administrativo en estos ámbitos se vuelve necesario para la ejecución de la política del Estado de bienestar, esto no puede ser operacionalizado con sentido sin conceder a los ámbitos afectados y a sus actores organizados mismos derechos de cogestión en las políticas correspondientes. En este caso, no se trata -sin querer ser peyorativo- ni de una societalización del Estado ni de una estatización de la sociedad -ambas serían simplemente desdiferenciación. Más bien se trata de un proceso, imprescindible para sociedades complejas, de acoplamiento y cruce de todos los sistemas sociales parciales -incluida la política- como actores de un mismo nivel. Es este ordenamiento igualitario primordial, convertido en una red de funciones indispensables, el que vuelve necesario un proceso de producción no jerárquica del orden social -un proceso que se diferencia fundamentalmente del modelo de formación de orden jerárquico basado en la decisión y las órdenes.

En las secciones siguientes se traerán a la discusión algunos elementos centrales de este proceso de formación del orden y orientación social no jerárquica. No se trata de recetas patentadas, sino del impulso hacia un discurso sobre el proceso de civilización de las sociedades desarrolladas.

\section{REFLEXIÓN: CIVILIZACIÓN DE LA AUTORREFERENCIA}

Cada teoría de la sociedad debe hoy enfrentarse con el hecho que las sociedades funcionalmente diferenciadas venden caro su notorio aumento en especialización, eficiencia y riqueza de opciones: el costo es una dinámica centrífuga que ha elevado de tal modo el monto de lo hipotético, de lo riesgoso y del peligro autogenerado en esas sociedades, que a muchos observadores ya les parece inabordable.

Bajo la distinción clave diferenciación/integración, las sociedades desarrolladas reaccionan a sus requerimientos críticos de integración -de ningún modo suficientes. Construyen instancias intermedias o sistemas de deliberación como dispositivos de coordinación y acuerdo intersistémico. Con ello, al menos se indican procedimientos y espacios sobre los cuales la intransparencia recíproca de los sistemas funcionales operativamente clausurados puede ser sobreescrita por medio de una tercera instancia. Hasta aquí sólo hemos aclarado cuáles son las precondiciones internas 
que deben ser logradas en los sistemas parciales, a fin de que ellos puedan tomar parte con alguna expectativa de éxito en discursos intersistémicos. El punto central es ahora que los actores o subsistemas no tienen incentivos a esforzarse por establecer acuerdos con otros actores, a no ser que ellos mismos se encuentren en una situación incómoda, de modo tal que vean lo que no ven y se den cuenta de aquello en lo que normalmente no reparan -esto es, los efectos de su propio modo de operación en su entorno.

A causa de su autorreferencialidad, los sistemas sociales complejos se remiten en primera línea a sí mismos, reaccionan a sus propios estados y perciben su entorno sólo muy selectivamente, según la medida de sus propios criterios de relevancia. Ciertamente el entorno aporta restricciones que conducen a la coevolución de sistemas en trayectorias precisas. Pero aun éste no es un enfrentamiento productivo, no permite reacción a los peligros e implica el riesgo de que la evolución termine en un callejón sin salida. Esta ceguera propia de los sistemas autorreferenciales -que se corresponde con la ceguera de la evolución natural- puede ser superada a través de que un sistema oriente sus operaciones, no sólo a sus otras operaciones propias, sino a sí mismo como un todo, es decir, como sistema en un entorno. Bajo esta guía, la unidad del sistema en el sistema se transforma en un punto de referencia arquimídico interno que posibilita, en cierto modo, sacar de quicio a esa unidad, en tanto ella es puesta a disposición de las operaciones del sistema.

Este paso hacia una representación interna de la propia unidad no se puede presentar de manera suficientemente dramática: con ella se transforma el entorno del sistema desde una no pertenencia o exclusión simple, hacia su posicionamiento como parte de la diferencia entre el sistema y entorno, y esto cambia al sistema desde una unidad autoorganizativa hacia una unidad autotransformativa que puede reaccionar a cualquiera de los efectos que ella produce en el entorno. Según Niklas Luhmann (1984: 617), esta capacidad del sistema de orientar sus propias operaciones a su propia unidad se llama "reflexión". La reflexión implica una forma de autoorientación, a través de la cual los sistemas tematizan su propia identidad y, de este modo, se disponen a que en el entorno existan otros sistemas, para los cuales cada sistema es su entorno respectivo. Con esto, se tiene la posibilidad de organizar un entorno más o menos apropiado, más a menos amenazante. La reflexión, en este sentido, es una forma elevada de autorreferencia, en la cual la 
autotematización de un sistema se dirige intencionalmente a su identidad y a sus efectos en su entorno (Teubner \& Willke 1984: 14).

Esto presupone ciertamente que los sistemas tengan determinados grados de libertad y con ello un ámbito de acción para el desarrollo de su identidad. A los seres humanos, en tanto sistemas síquicos complejos, este supuesto nos parece dado, tanto que no tememos presionarlo con educación, formación de personalidad, psicoterapia, pero también con intervenciones masivas en cárceles y campos de readoctrinamiento. ¿Pero se puede educar a los sistemas sociales? ¡Se puede! En las empresas eso lo hacen los asesores empresariales, en partidos, sindicatos y otras organizaciones como escuelas o la administración pública, reformadores o innovadores, en los sistemas sociales como economía, ciencia o el sistema de salud, la esfera pública a través de crisis o innovaciones internas.

Se sabe, por otro lado, que el arte de la educación de los sistemas sociales no está altamente desarrollado, en especial en lo que se refiere a los sistemas funcionales y a la sociedad como un todo. Ahí los supuestos para una representación adecuada de sus entornos son apenas visibles. Esto se puede ver en la conocida incapacidad de los sistemas sociales de registrar y reaccionar ante las molestias y peligros físico-biológicos del entorno. Pero no sólo en ello. También su sensibilidad para las consecuencias de su operar frente a los seres humanos no está altamente desarrollada, ya sea en las escuelas, iglesias, partidos o, como muchos dicen, incluso en las universidades.

La capacidad de empatía, de observación de acontecimientos desde la visión de otras personas o roles, la exigimos a seres humanos adultos y civilizados. ¿Por qué no también a los sistemas sociales? Las consecuencias de esta torpeza de los sistemas sociales pueden ser tremendas, tanto como aquellas de los individuos. Un aumento de la capacidad de reflexión de los sistemas sociales parece por esto especialmente urgente. La reflexión está llena de presupuestos, exige inversiones en dispositivos de autoesclarecimiento sobre las consecuencias sistémicas externas del sistema, exige la capacidad de autoobservación y autodescripción y, finalmente, de 'comprensión' de otros sistemas.

A través de la autoobservación, un sistema deduce su unidad interna sobre el trasfondo de la diferencia con su entorno. La observación se permite todo aquello que se presenta en la forma de cualquier diferencia o que es puesto en esa forma, en tanto precisamente esa diferencia hace sentido para los criterios de operación de un sistema 
social. La unidad del sistema se deja descubrir cuando el sistema se desprende de su entorno, algo así como en la idea de figura y fondo, o como unidad de procesamiento de un sentido específico, el cual se diferencia de otros dominios de sentido a través de propios criterios de comunicación. Así también, la observación sociológica de lo que constituye una familia, una organización, un sistema funcional o una sociedad, depende de si se tiene éxito en diferenciar dominios de sentido específicos, los cuales constituyen contextos de comunicación independientes.

La unidad de un sistema puede observar al sistema si es la unidad de una diferencia. Un observador puede observar esa unidad como diferencia sólo en referencia a otra unidad distinguible de aquella unidad, es decir, nuevamente como diferencia. Así, por ejemplo, la unidad de los roles del productor y consumidor, los cuales son observables como 'mercado', se separa de otras formas posibles de unidad, como, por ejemplo, la repartición, la planificación, el potlatch o la grants-economy. Así también, la diferencia entre hombre y mujer indicada como 'unión natural' sólo es observable porque ella se distingue de otras formas de unidad, como la pareja, la amistad o las relaciones de trabajo.

Se está en dificultades, por tanto, al observar la unidad del sistema y entorno. Ella es sólo observable para otros sistemas y otros entornos, es decir, estrictamente: sólo cuando en el entorno de un sistema también son reconocibles otros sistemas y un sistema concluye que para otro sistema sus entornos deben verse de otro modo. Precisamente esta forma de pensar parece estar en el fondo de una precisa reconstrucción de la formación de la identidad del niño en Jean Piaget (cf. Piaget 1973: 222ss., 1971: 349ss, especialmente en torno al proceso de clausura de sistemas abiertos). No se trata de que el niño, a través de la investigación de sus distintos espacios cercanos, descubra paulatinamente su diferencia con el entorno; esencial es que se observe en la persona de la madre otra unidad del entorno, cuyo entorno se diferencia del propio. También la diferencia en la capacidad empática de los hijos únicos y otros niños observable a menudo, puede relacionarse con esto.

La reflexión se puede describir más precisamente entonces como la observación de las consecuencias de la propia identidad en el entorno (incluidos los efectos especialmente relevantes de estas consecuencias en el sistema mismo), por diferencia a las consecuencias que otros sistemas producen en sus entornos. El punto decisivo de la especificidad de esa reconstrucción para los sistemas autorreferenciales está en que esos 'otros' 
sistemas pueden ser identidades diferenciadas del mismo sistema. La reflexión se basa efectivamente en que un sistema reintroduzca permanentemente las diferencias entre el sistema y el entorno en el sistema, y que lo haga bajo el punto de vista de comparación de posibles identidades. Un efecto de la educación, en el sentido de un proceso de autotransformación, sólo tiene lugar cuando la autoobservación permanente de un sistema conduce a que desde el variety pool o espacio de contingencia de las posibles identidades, se realicen aquellas que permitan una mejor adecuación a los entornos percibidos.

En las empresas este 'proceso educativo' conduce a la adecuación al mercado, en los partidos a una adecuación a los movimientos de los electores, en las universidades a la adecuación a la conducta de los estudiantes o a nuevas necesidades de la economía. Todo esto sería muy bien conocido y no se diferenciaría de la simple evolución si no hubiese una diferencia decisiva: la reflexión permite transformaciones previsibles y la interrelación de identidades virtuales, de modo tal que parecen realizables una determinada dirección de desarrollo y con ello ciertas 'estrategias de evolución' por medio de la pura adaptación.

En relación con las sociedades modernas, esto significa sobre todo que los actores sociales definen sus propios intereses diferenciadamente y los pueden seguir a través de estrategias de acción totalmente distintas. Pueden tratar con una estrategia de maximización, en una perspectiva de corto plazo maximizar las ventajas propias y minimizar aquellas del contrincante. La interrelación de distintos sistemas y actores se transforma con ello en conflicto y queda definido como un juego de suma cero (lo que uno gana, lo pierde el otro: la suma de ganancias y pérdidas es cero). Pero es posible también una estrategia de optimización que se basa completamente en otras premisas:

1. No se trata de un conflicto aislado, sino de un continuo procesamiento de contradicciones.

2. Por ello es adecuada una perspectiva de mediano o largo plazo para el cálculo de costos y beneficios.

3. En situaciones de conflicto complejo, las constelaciones de suma cero son improbables.

4. La cooperación, a pesar de los conflictos puntuales, aumenta la probabilidad de más ganadores (juego de suma positiva) y la optimización de las utilidades combinatorias (en detalle para esto Axelrod 1984, Axelrod \& Keohane 1985). 
El ejemplo clásico para estas estrategias diferenciadas y sus consecuencias es naturalmente el conflicto entre trabajo y capital, entre sindicatos y asociaciones de empresas. En ambas partes se construyen paulatinamente capacidades de reflexión y con ello la posibilidad de disminuir las consecuencias externas de la propia acción y de tomar en cuenta la posición del contrario en el propio cálculo de decisión, y esto en razón de que es seguro que se tenga que ver con él nuevamente: "Para que la cooperación se pruebe estable, el futuro debe tener una sombra suficientemente larga" (Axelrod 1984: 174). Para la comprensión de una sociedad desarrollada, es importante ver que una estrategia de optimización basada en la capacidad de reflexión se transforma en una seria opción para los actores relevantes de cada sistema social parcial. Es seria porque los sistemas sociales de alta complejidad dinámica e interconexión se desvían cada vez de modo más pronunciado hacia el futuro y por ello dependen de un futuro operacional, es decir, de la cooperación con otros constructores del futuro.

El significado particular de la capacidad de reflexión como conciencia de una identidad dependiente de criterios seleccionados sólo emerge cuando la reflexión, como modo de orientación sistémica, se pone en contraste con otras formas de orientación. Con ello, especialmente el muddling through tiene ciertamente la ventaja de ser un procedimiento en cierta medida natural y modesto de los sistemas sociales complejos (Lindblom 1965). Pero a través de su estrecho horizonte temporal y su tratamiento incremental de problemas, esta forma corre el riesgo de ser sorprendida por una dificultad imprevista e insuperable: la reflexión apunta especialmente a esa difícil forma de aprendizaje o de autoeducación que exige transformaciones de los procesos sistémicos propios, de las prioridades y de las posiciones en referencia a futuras realidades, una forma de aprendizaje que exige un contexto que vaya más allá de la identidad propia. Producir una relación consigo mismo con el objetivo de comprenderse como una parte funcional específica de un todo interconectado, exige visiones llenas de presupuestos en relaciones que están vinculadas con una comprensión de las condiciones de desarrollo y de función de otros sistemas afectados. Esto toca a los miembros del sistema social familiar, al sistema empresarial, a los ministerios como parte del sistema político administrativo, tanto como a zonas funcionales del sistema sociedad.

La reflexión conecta opciones de acción generales y la variedad de opciones de sistemas parciales especializados a las capacidades de 
autocontrol y autolimitación: en los criterios de relevancia específicos de los subsistemas y en las premisas de decisión son construidas aquellas condiciones de entorno como restricciones internas, las cuales bajo el punto de vista de los contextos necesarios y de la inevitable coordinación del todo requieren de consideración recíproca ante las condiciones de composición de las otras partes. La reflexión presupone la modelación interna de las condiciones de función de sistemas 'extraños' y actúa como autoselectividad exigida de los sistemas funcionales: ella selecciona desde el espacio de opciones conectables al interior del sistema y conduce, en el mejor de los casos, a una óptima distribución de costos y beneficios de los sistemas parciales involucrados.

No está de ningún modo claro, por ejemplo, si la ciencia ya ha desarrollado esa capacidad de reflexión o no. La reflexión no supone únicamente el autoaseguramiento de los propios fundamentos operativos, por ejemplo, en la forma de teorías científicas; exige la consideración de las consecuencias de la propia acción sobre el entorno, esto es, respuesta a la pregunta por los límites de la ciencia, por ejemplo, en las recombinaciones genéticas o en los experimentos en embriones humanos. Algo similar se produce en la política: si la obligación de una estrategia político-militar de una mutual assured destruction (MAD) es soportable para la sociedad en general o no está al menos en duda. O la tecnología: si una determinada tecnología nuclear debe ser realizada o no, no puede ser ya dejada solamente a lo tecnológicamente posible. Se pueden encontrar fácilmente ejemplos para cada sistema funcional de la sociedad, los que establecen claramente la necesidad de una autoorientación reflexiva, pues cada sistema funcional puede hacer peligrar a otros sistemas o a la sociedad en general si es que maximiza 'sin pensarlo' -esto es, si se fija puramente en su propio modo de operación autorreferido- sus propios beneficios a corto plazo, su limitada racionalidad.

Dos importantes ejemplos dejan especialmente clara la relevancia del concepto reflexión como condición de posibilidad de una sociedad racional. Por una parte, el surgimiento descontrolado de catástrofes ambientales, por otro lado, la autoamenaza atómica de la sociedad. La estrategia global político-militar de máxima disuasión (MAD) se basa en la amenaza de un contragolpe atómico destructivo por un ataque masivo del contrincante de turno. Las sociedades desarrolladas se dirigen con esto hacia un callejón evolutivo sin salida, el cual incluye las posibilidades reales de una -casual o incremental o deseada-destrucción mutua. Desde hace un tiempo la situación se pone más explosiva porque en el 
pensamiento estratégico actual se despliega una significativa reorientación de sistemas puramente ofensivos $-\mathrm{y}$ la desatención de sistemas defensivos estratégicos- hacia una mezcla de sistemas ofensivos y defensivos. Puesto que nadie sabe cuán efectivos son o serán los sistemas defensivos, cambia el contexto general de disuasión. Dentro del marco de MAD, la disuasión se basa en la expectativa segura de un contraataque mortal. Previsibilidad y calculabilidad son los garantes del funcionamiento de MAD, además la incalculabilidad e inseguridad son fundamentos de la disuasión cuando los sistemas ofensivo y defensivo se mezclan.

El cálculo estratégico del MAD es claro y simple, quizás demasiado simple: quien pega primero muere segundo. El cálculo estratégico de una mezcla de sistema ofensivos y defensivos se basa, por el contrario, en la incalculabilidad fundamental de un primer golpe y precisamente esto puede conducir al planificador estratégico a postular una cada vez más alta necesidad de misiles intercontinentales ofensivos frente a los sistemas defensivos (en detalle para esto Willke 1988b).

Se podría decir que, a cada sistema político afectado y a cada actor político responsable, aparece clara ante los ojos la locura de este ordenamiento. Pero esto no es así. Es importante ver que, al lado de un cúmulo de otros factores, el torpe modo de operación autorreferido de los sistemas político-militares junto con su tendencia normal hacia estrategias de maximización es lo que, en realidad, conduce la incomprensible autoamenaza hacia una forma militarmente racional de confrontación y por ello todavía difícil de superar.

Tan sólo cuando la propia dinámica y racionalidad de los complejos político-militares son contenidas y en este sentido civilizadas a través de una reflexión de las consecuencias de una estrategia de maximización, hay una oportunidad realista para formas racionales de confrontación. Entretanto, parece ser que esta reflexión es efectivamente al menos imaginable: en el caso de los EE.UU., impulsada por una clara pérdida de legitimidad de las estrategias de disuasión globales, en el caso de la Unión Soviética, impulsada por los inmensos costos tecnológicos y económicos de esta estrategia. Cuando en 1988 hubo por primera vez una mínima reducción de los sistemas de armas atómicos, esto se pudo ver como un aumento en la capacidad de reflexión de los sistemas políticos desarrollados.

Un contraejemplo es la tan riesgosa como autoamenazante incapacidad de las sociedades desarrolladas de controlar efectivamente la destrucción de su ambiente físico-biológico. En esta área se presentan 
ante nuestros ojos día tras día ejemplos de estrategias torpes de maximización al corto plazo -estrategias que no sólo son implementadas por empresas privadas que maximizan sus propias utilidades, sino también por burocracias, asociaciones, partidos y con toda claridad también por una sociedad frente a otra (como Estados costeros en mares y grandes ríos o miembros de Comunidades Europeas). Esos actores actúan según la lógica de un juego de suma cero, el veneno que reparten por ahí no lo tienen que limpiar ellos mismos.

Luhmann (1986) ha mostrado detalladamente porqué es especialmente difícil la comunicación ecológica para las sociedades funcionalmente diferenciadas. La racionalidad reflexiva sólo sería alcanzada "cuando la sociedad pueda tener en cuenta las consecuencias de sus efectos sobre el entorno" (Luhmann 1986: 247). Seguramente Luhmann concordaría que la precondición de todos los esfuerzos por la racionalidad sería que se comprenda "por qué ella es y sigue siendo improbable" (Luhmann 1986: 258). Pero naturalmente esto no es una justificación para permanecer en las razones que impiden esto. La pregunta es, cuánto tiempo se pueden permitir esta ignorancia colectiva las sociedades desarrolladas, cuando las consecuencias de sus efectos para el entorno las obligan despiadadamente a no tomar en consideración los costos para su racionalidad.

\section{INTERVENCIÓN CONTEXTUAL: CIVILIZACIÓN DEL PODER}

¿Pero de qué razón se trata, una económica, científica, religiosa, artística? El problema es obvio, hay muchas y muy distintas racionalidades, cada partido, cada disciplina, cada rama económica, cada ideología tiene la suya. El problema central de las sociedades desarrolladas es cómo esas racionalidades divergentes puedan ser traídas a un discurso instructivo, en el cual la racionalidad del sistema general tenga una oportunidad.

Para reconocer el alcance del problema, es necesario despedirse de una solución en cierta medida cercana y natural, esto es, que la política sea la que, en una agregación y mediación de intereses y realidades sociales divergentes, decida en nombre del bien común y que las opiniones desviantes o contradictorias sean traídas a razón con los métodos de fuerza del poder político. Bien se ha dicho que esta solución no es totalmente disparatada, ella ha producido un procedimiento constitucionalmente controlado y legítimo del procesamiento de conflictos, el cual, frente a la clásica tarea estatal del 'buen policía', funciona mejor que otro sistema, especialmente en lo referido a la 
imposición del orden jurídico, al ejercicio del monopolio de violencia, al nivel de impuestos, y las tareas elementales de la seguridad social mínima. Estas tareas no se han transformado, como tampoco lo ha hecho la necesidad del proceso político. Pero lo que, en este siglo, y especialmente después de la segunda Guerra Mundial, se ha transformado fundamentalmente, es el grado y cualidad de la complejidad y riesgo social, y con ello las exigencias a las estrategias de orientación.

El sistema político se ve confrontado con 'nuevas tareas del Estado, nuevas tareas y exigencias.' Una y otra vez esto conduce a una situación en la que se diagnostica una sobrecarga del sistema político, visible en la ingobernabilidad, crisis de legitimación, crisis de conducción, fracaso del Estado y en una crisis de sentido generalizada. A estos diagnósticos subyacen dos premisas: por una parte, que el sistema político sería fundamentalmente el responsable por la solución de los problemas sociales, más precisamente por las nuevas tareas de orientación social del Estado, y por otra, en el convencimiento de que por esto la política debería hacer más -más de lo mismo, esto es, más leyes, más dineros públicos, más administración. Ambas premisas son, según la perspectiva teórica desarrollada aquí, incorrectas. Ellas conducen a consecuencias que agravan el problema en vez de hacerlo manejable. Se desvían de la especificidad y novedad del desarrollo social de la última década, cual es que no sólo la política no puede asumir más la necesaria función de integración y orientación, sino que ningún sistema parcial de la sociedad desarrollada lo puede hacer. Entendemos esto como punto central para la comprensión de las sociedades desarrolladas, vuelvo sobre ello ahora.

Antes que nada, hay que mencionar la pregunta cómo un sistema funcional operativamente clausurado puede influir calculadamente en otro. Si no existiera esta posibilidad de una influencia calculada, sólo quedarían dos posibilidades: evolución natural o desdiferenciación regresiva. En efecto, después de las fuertes desilusiones del pensamiento planificador, muchas propuestas se dirigen hacia esta alternativa: "para la sobrevivencia de la sociedad basta la evolución" (Luhmann 1984: 645). ¿Pero basta la evolución para sistemas sociales como las sociedades desarrolladas? ¿Quién podría creer hoy aún en eso? La confianza en la simple evolución ha sido sacudida de muchas maneras, la cuota de quiebres de costos ocultos y de inexorabilidad de la simple evolución es muy alta. Por otro lado, los resultados de las desdiferenciaciones practicadas en las sociedades socialistas hacen de este modelo cualquier cosa, menos atractivo. ¿Qué hacer entonces? ¡Desarrollar una nueva 
opción! Introducir esta opción bajo la palabra clave orientación contextual. Presupuesto de cada orientación es la posibilidad de un efecto calculado en otro sistema. La plausibilidad de cada opción alternativa depende de que, por una parte, se evite la desdiferenciación y con ello la amenaza de la autonomía del sistema funcional, y por otra, se constate que las intervenciones a pesar de ello son posibles.

Punto de partida es la dinámica propia, la propia legalidad y clausura operativa de los sistemas funcionales especializados. A base de la circularidad de su modo de operación, surge el peligro de un regreso infinito de autorreferencia que siempre corre en sí misma hacia adelante y hacia atrás. Para evitar este peligro, los sistemas sociales complejos necesitan de contacto con el entorno $\mathrm{y}$, con ello, de una apertura al entorno parcial y específico. A través de los contactos con el entorno son introducidas interrupciones de interdependencia en los surcos de autorreferencia, es decir, reglas de detención y nuevos impulsos para los procesos sistémicos recursivos. Los contactos con el entorno actúan como interpunciones de los procesos sistémicos internos. Deben, por un lado, ser legibles en el lenguaje (esta vez en las diferencias relevantes) del sistema para poder ser percibidos, y por otro lado, ser incorporados como información contextual en el modo de operación circular del sistema para tener algún efecto.

Cada intervención desde afuera debe superar una estructura causal sistémicamente específica para que pueda notarse en el sistema, ella es dependiente en sus efectos de los estados internos y del modo de operación del sistema afectado. Así, por ejemplo, cada intento de la política de intervenir en constelaciones problemáticas complejas choca con la barrera de la propia legalidad y autoorientación de los sistemas sociales. Esto hace difícil las intervenciones políticas, pues ellas deben ahora organizarse sobre la base de la clausura operativa y dinámica propia de los sistemas afectados. Las intervenciones son sólo posibles en la forma de una condicionalización de las condiciones contextuales que entran como diferencias observables en la base de datos del sistema en cuestión. La dificultad de la intervención en sistemas autorreferenciales se deja expresar bien en el sentido de Heinz von Foerster: a causa de su clausura operativa y de la estructura de la referencia compleja interna, los sistemas no pueden ser influidos causalmente de modo lineal desde afuera. En tanto sistemas no triviales, ellos no siguen el simple esquema input-output de los sistemas mecánicos, sino que muestran una lógica procesual 
autónoma y de ello derivan una conducta de sentido propio, la que establece estrechos límites para el uso del poder directivo.

Parece por tanto apropiado desarrollar una concepción adecuada de la intervención en los sistemas sociales complejos. Ella ya no debe basarse más en la imagen de una orientación causal directa, sino en la representación de una guía a la autoorientación. Los sistemas complejos ligados a su modo especializado de operación sólo pueden 'comprender' y evaluar las influencias externas como ofertas de información si es que ellas se presentan en una forma que haga sentido a los esquemas de búsqueda (criterios de observación, diferencias directivas) del sistema intervenido. Ellas deben por tanto ser relevantes como condiciones contextuales del modo de operación del sistema y, como tales, ser utilizadas por el sistema mismo como interpunciones de sus procesos autónomos de orientación.

Cada intervención no trivial se sitúa ante una paradoja bloqueante: ella quiere producir algo que no puede producir. Tan sólo los nuevos desarrollos teóricos sistémicamente orientados parecen permitir comprender las intervenciones dirigidas en sistemas autónomos como estrategias de desparadojización de ese dilema. Ellas pueden ser exitosas si respetan y refuerzan la autonomía del sistema intervenido. La historia de intervenciones correctivas a través de medidas jurídicas políticamente definidas se asemeja a aquellas en la pedagogía, la medicina, la criminología, la política de desarrollo y la terapia: nada nuevo desde Prokrustes. También el pensamiento sistémico ha apoyado esa prevención contra correcciones externamente dirigidas centradas en el énfasis en la adecuación al entorno. Tan solo la mirada paulatina sobre las especificidades del modo de operación de sistemas complejos autorreferenciales, contribuye a llevar la problemática de las intervenciones correctivas a un marco de referencia más apropiado, a aquél de las condiciones de posibilidad de una estimulación controlada a la autotransformación de sistemas autónomos.

Las intervenciones correctivas buscan cambiar el estado de un sistema psíquico o social no-trivial, cuya lógica de operación no puede ser comprendida o dominada definitiva o esencialmente por el actor interviniente. La intervención es, por tanto -como muestran suficientemente la psicoterapia, en la pedagogía o en la política de desarrollo- obligadamente acción bajo inseguridad y riesgo. En principio, la intervención confronta al sistema a intervenir con el riesgo de someterse a observación y comunicación que no proviene de los plexos de referencia internos, sino de estímulos externos. Un sistema asume ese 
riesgo sólo bajo condiciones especiales, de las cuales tal vez la más importante es que el mismo sistema intervenido perciba una situación problemática que requiere de ayuda. Tan importante como ello es que la intervención genera un riesgo también para las expectativas del actor interviniente, pues en los complejos contextos de consecuencias, cada acción tiene más consecuencias imprevistas que previstas. Es por tanto totalmente posible -y esto lo confirma la diaria praxis política, pedagógica o médica- que la intervención produzca nada, algo distinto o lo contrario de lo que se esperaba. También el actor interviniente se debiese pensar, actuará sólo bajo condiciones especiales que eviten su riesgo. Que lo último, en todo caso, sólo suceda a veces, se puede deber a que el actor interviniente no asume él mismo el riesgo, sino que lo desplaza a un tercero, al futuro o, con especial ironía, al mismo sistema intervenido.

Todo esto se puede ver en el modo de trabajo del sistema político. Las intervenciones políticas -a través del medio poder jurídicamente codificado- en áreas de problemas como el terrorismo político, el tráfico de drogas, el tratamiento psiquiátrico estacionario, el desempleo estructural y sectorial, el envejecimiento industrial, etc., no han sido, desde hace muchos años, precisamente exitosas. No se trata de reprochar a la política con esta constatación. Por el contrario, se trata de entender que las intervenciones políticas tradicionales de tipo autoritativo y directivo no pueden ser exitosas en esos campos de problemas altamente complejos y con dinámicas propias. No se requiere de una política de más de lo mismo (porque la promesa rutinaria de los políticos exitosos, 'trabajar más y más duro' es totalmente sin sentido) u otra política (porque también los cambios de gobierno y la promesa de la oposición de turno de una política totalmente distinta cambia demasiado poco).

Se requiere más bien de una modestia de la política, de una civilización del poder político, lo cual significa, en la primera línea, que el poder produce menos cambios de lo que quien tiene el poder y sus teóricos quieren aceptar. En sistemas altamente complejos, la aplicación del poder es paradójica. Mientras más dosificadamente y cuidadosamente se aplica, más efectivo es. ¿Por qué? Porque la aplicación del poder en el contexto de los sistemas autónomos no produce conformidad, sino problemas de aceptación o, puesto de modo tradicional, contraposición. La aplicación trivial y trivializante del poder político cubre tan sólo la arrogancia del poder y socava su propio efecto. La generalización del poder político, como instrumental de intervención, parece estar sometida a límites inmanentes de manera análoga (sobre un nivel bajo de 
emergencia) a la generalización de la violencia física a través de un poder político centralizado. Cada aplicación estatal de la violencia física demuestra la sobrevaloración simbólicamente generalizada del poder político, demuestra con ello la debilidad de la fuerza: "El poder fundado en la violencia tiene la propiedad de un principio de orientación relativamente simple de toma de decisión... En un sentido genético y en sentido de una innegable condición mínima, el sistema se basa en la violencia, pero no puede ser controlado a través de la violencia." (Luhmann 1975: 66ss). Análogamente, en sentido genético, las sociedades de bienestar se basan ciertamente en el éxito del poder político generalizado, pero ellas no pueden ser controladas por medio del poder. Efectivamente, estas sociedades están en muchos sentidos fuera de control y parece ser tiempo de mirarlas según formas de orientación propias de sistemas altamente complejos.

Muchas teorías del poder, y especialmente aquella de Michel Foucault, pasan por alto que, en sistemas desarrollados, las relaciones entre poder y orientación sistémica han llegado a ser difíciles (en detalle aquí Honneth 1985). Como Amitai Etzioni (1968) ya lo formuló hace veinte años, la capacidad de orientación activa presupone un aumento simultáneo de consenso y control. En la perspectiva teórica de la diferenciación, esto puede especificarse: en lo que toca al proceso político, esto es, al modo de operación del sistema político, éste se ve estorbado más bien por poco que por mucho poder. Más poder significa mejores capacidades y dispositivos de procesamiento y generación de información (para la Alemania Democrática, por ejemplo, un servicio científico estatal de la calidad del Congressional Research Service norteamericano), una más clara separación entre gobierno y oposición, un esclarecimiento de la espesura del entramado político (Scharpf 1985), un aumento eficiente y efectivo de las burocracias políticas y de los procesos de decisión. Objetivo de este aumento del poder del sistema político no es dominar a la sociedad -en vistas a la pluralidad, la diferenciación y autonomía de los actores sociales esto está excluido. Más bien se trata de hacer más independiente a la política y de hacer con ello lo mismo a los otros sistemas sociales parciales frente a la política, para entonces, sobre la base de interdependencias e independencias mutuas, poner en movimiento discursos de acuerdo y orientación.

Mientras Axel Honneth ve en Foucault una "teoría de sistemas dirigida únicamente a procesos de orientación" (1985: 217), a la moderna teoría de sistemas se le puede reprochar aún que ella ha subvalorado 
hasta ahora los procesos de orientación en sistemas complejos. La fijación con el poder (tanto en Honneth como en Foucault) desconoce justamente que el poder es sólo un recurso de orientación entre muchos otros; que el poder en los sistemas sociales complejos no se puede organizar más de modo jerárquico; que la utilización del poder en sistemas sociales y tecnológicos complejos puede ser altamente riesgosa y contraproductiva; y que en las sociedades diferenciadas, el poder de los sistemas políticos en relación con su función, es más bien deficitario antes que abundante. Incluso una pregunta de rango menor como aquella del tratamiento de ocupaciones ilegales muestra cuan precario, inseguro y dependiente de situaciones de acuerdo público es el ejercicio del poder político.

$\mathrm{Al}$ proyecto de una civilización del poder pertenece también el logro de una visión de la relatividad del poder en las sociedades desarrolladas. Si los sistemas diferenciados están compuestos de muchos centros de actividad autónomos y con sentido propio, ellos derivan hacia 'sociedades policéntricas' (Polanyi 1951: 180ss). Con ello, la intervención política se hace más difícil y problemática. Con todo esto no se quiere establecer la idea de una incapacidad del poder, pero una adecuada crítica de él -como una crítica del conocimiento, de las creencias, del dinero, etc.- supone perspectivas altamente positivas frente el juego de autonomía parcial e interdependencia funcional de esos distintos medios de orientación.

Una vez más hay que subrayar que el punto de partida para intervenciones correctivas en los sistemas autónomos es una paradoja: apuntan a intenciones no intencionales. En un sentido estrecho, es imposible intervenir intencionadamente en un sistema operativamente clausurado, pues este sólo toca su propia melodía y puede escuchar sólo su propia música. De modo similar a la política de desarrollo, la terapia y el desarrollo organizacional o la educación (en detalle para estas analogías Willke 1987a, 1988b), para la orientación social se presenta el problema de cómo pueden ser desplegadas las exigencias paradójicas de ayuda para la autoayuda, o determinación para la autodeterminación, o la educación de adultos, o la guía hacia la autotransformación, de manera tal que la intención de intervención no desautorice su posibilidad y éxito.

Justamente, y al contrario de las representaciones de la intervención desarrolladas hasta hoy, hay que considerar en el caso de sistemas autónomos no triviales, que cada intervención externa depende de si logra presentarse como evento en campo de posibles percepciones del sistema intervenido e introducirse como información en los ciclos operativos de ese sistema. Las intervenciones políticas con el medio derecho ya no 
logran esto en muchos casos críticos: dificultades de imposición, problemas de aceptación, déficits de implementación, estrategias de desviación de las áreas intervenidas y hasta oposición abierta u oculta son las consecuencias. El punto decisivo es que las dificultades derivadas de la aplicación de más poder o de otras intervenciones no decrecen, sino que se refuerzan, de modo que se llega a lo que Jay Forrester (1972) describe como "círculo vicioso".

Es necesario aquí tener claro que las consecuencias de las intervenciones no dependen en primera línea de las intenciones de la intervención, sino del modo de operación y de las reglas de autoorientación del sistema en el que se debe intervenir. Las buenas intenciones no son garantía de éxito -ni en la educación, ni en la ayuda para el desarrollo, ni en la política. Para activar cambios permanentes, las propuestas externas deben ser transformadas en informaciones internas que induzcan cambios en las reglas sistémicas, y esto, en todo caso, sin destruir la especificidad de las reglas sistémicas existentes.

En educación o en el desarrollo organizacional (asesoría organizacional), una comprensión intuitiva puede indicar que la estabilidad de los cambios sólo es alcanzable en consonancia con la identidad autónoma del sistema afectado. La orientación contextual presupone discrepancias dosificadas que puedan ser comprendidas en el sistema e introducidas en su propia lógica de operación. A nivel de las sociedades desarrolladas, las cosas se ponen más enredadas y constituye una gran dificultad ver que la política de intervención y bienestar, como intento de influir en campos problemáticos, está sujeta a las mismas restricciones.

Las dificultades nombradas de la intervención dirigida y de la recomendada nueva humildad de la política no obligan, sin embargo, a una renuncia a la intervención. Las intervenciones contextuales que en forma de una política de opciones cambian las condiciones contextuales de un sistema o de áreas problemáticas y que ponen otras opciones en juego, son sin duda posibles. En otros trabajos he mencionado esto detalladamente, como la idea de la "orientación contextual descentralizada" (Willke 1984a, 1986b, 1987b). Aquí se trata más bien de visualizar la estrecha conexión en las condiciones de posibilidad de la reflexión y de la intervención contextual. Si bien la autolimitación de un sistema interviniente -especialmente de la política- a desarrollar una intervención contextual, como también la capacidad correspondiente del sistema intervenido de reaccionar adecuadamente a esa política de 
opciones, presupone reflexión en los sistemas sociales afectados. Y tan solo la capacidad de una intervención reflexiva en la lógica de operación de otros sistemas posibilita a un actor establecer intervenciones de tal modo que los procesos de cambio no se bloqueen, sino que entreguen estímulos a la autotransformación.

Si esta forma de civilización del poder para intervenciones en campos como la educación (por ejemplo, la eliminación del castigo físico), la resocialización (eliminación de los suplicios), la terapia (reforma psiquiátrica y procedimientos de la psicología humanista), las relaciones de trabajo (acuerdos calificados) y en otros campos es posible de realizar, ¿por qué no puede ser posible una correspondiente civilización de las relaciones de intervención en sistemas sociales parciales? Seguramente fuertes problemas, conflictos y costos humanos y sociales han llevado a las actuales reformas en las áreas nombradas. Pero, ¿alcanza el grado de patología de las sociedades desarrolladas para no esforzarse seriamente por formas adecuadas de acuerdo y reintegración? ¿No son precisamente los problemas más urgentes y masivos de las sociedades desarrolladas (como el armamentismo y el peligro de guerra, la destrucción del medioambiente, las enfermedades civilizadas, las tecnologías riesgosas, el desempleo estructural, etc.) constatación suficiente de una incapacidad de los procesos políticos actuales de producir suficientes formas de orientación para una renovada capacidad de desarrollo de esas sociedades?

Seguramente este texto tampoco ofrece recetas patentadas. Se debe Al menos, sin embargo, mencionar para concluir, la idea de los discursos sistémicos en sistemas de deliberación, de modo de mostrar que hay planteamientos para el procesamiento de los difíciles problemas de orientación de las sociedades desarrolladas y que aquellos se pueden poner en práctica.

3. DisCURSOS SISTÉMICOS: LINEAMIENTOS FUNDAMENTALES DE LA CIVILIZACIÓN DE LAS SOCIEDADES DESARROLLADAS

Los discursos sistémicos indican el intento de superar las racionalidades e intereses divergentes de actores colectivos organizados en sistemas de deliberación. Los sistemas de deliberación son sistemas de tercer tipo, 'terceras instancias' que consisten de las relaciones de interacción de los actores involucrados, los que desde ahí ganan su identidad, historia y racionalidad. Su problema funcional central es estabilizar un acto de 
balance: ni alejarse mucho ('desprenderse') de los sistemas afectados ni dejarse acaparar por uno o varios actores.

En la tormentosa discusión hasta ahora desarrollada sobre los presupuestos y consecuencias de la autorreferencialidad de sistemas sociales complejos operativamente clausurados, la pregunta por la 'interacción instructiva' de tales sistemas constituye hasta hoy un punto tan importante como poco claro. Mientras hasta aquí las ideas de reflexión, intervención contextual y sistemas de deliberación más bien se han visto como pilares provisorios de la posibilidad de una interacción instructiva, quisiera ahora ir un paso más allá al proponer, con Rainer Eichmann (1989: 138ss), conectar esos momentos a un modus operandi para la coordinación y orientación de sistemas autónomos parciales. Tan solo la conexión de reflexión, intervención contextual y discurso, constituye un modo procedimental en el que la paradoja de la compatibilidad - ¡no del acuerdo!- de racionalidades divergentes puede ser desplegada.

La reflexión, como capacidad de observación y procesamiento productivo de las consecuencias externas de una identidad específica, logra para un sistema la posibilidad de poder tomar distancia de sí mismo y probar su modo de operación frente a alternativas compatibles. Esa capacidad de reflexión de identidades alternativas prepara en cierta medida en piso para que una intervención contextual pueda ser fructífera, pues un sistema (sea una persona, organización o un sistema parcial) que se sujeta fijamente a una identidad, enfrentará cada intervención en tanto 'ataque externo' con una reacción de inmunidad. Sólo una medida de soberanía (esto es de distanciamiento) frente a sí mismo abre al sistema la posibilidad de seguir siendo el mismo, siendo otro. Estamos acostumbrados a esperar esta apertura sólo en el contexto de la terapia, de la educación o de la convalecencia. Hay que primero acostumbrarse a la idea de que también los sistemas sociales pueden ser educados para un avanzado grado de civilización.

La intervención contextual es la única forma de intervención que respeta estrictamente la especificidad de las distinciones directivas diferenciadas y la autonomía de las lógicas de operación que de ello surgen, y es la única que presupone a ambos lados, el del interventor y del intervenido, la capacidad de reflexión. La intervención contextual debe satisfacerse con operar sobre los contextos, exige por tanto una autolimitación del actor interviniente en lo que a la dirección y cualidad de la intervención se refiere, así como también una 'comprensión' del modo de operación del sistema intervenido, a fin de que la intervención sea 
realizada de forma tal que para el sistema intervenido se haga accesible. Así, por ejemplo, un largo y difícil proceso de aprendizaje condujo a las asociaciones de empleadores al convencimiento de que en enfrentamiento con los sindicatos no se podían implementar intervenciones que perjudicaran la capacidad de organización de estos últimos. Ellas atacaban los nervios del modo de operación de los sindicatos y eran por tanto inaceptables. En los sistemas de deliberación de 'acciones concertadas' (de la ley de estabilidad) se estableció finalmente la idea compartida, y por ello respetada por todos los actores, de que una alta capacidad de organización de los sindicatos los llevaría a ser partners competentes y confiables -que harían por ejemplo menos probables las huelgas incontrolables (en detalle Willke 1983: 128ss).

Si no se quiere dejar a la casualidad, por un lado, la formación de la capacidad de reflexión y, por otro, la educación de los actores hacia una autolimitación a la intervención contextual, parece aconsejable trasladar un problema social relevante para los sistemas afectados a un contexto procedimental, en el cual la confrontación quede subordinada a restricciones productivas. Un proceso penal sigue por ejemplo esta idea procedimental, en la cual los actores, a pesar de intereses altamente divergentes, operan en conjunto para sacar de ello una 'verdad' común (en la cual la capacidad reflexiva del fiscal se le exige también traer a colación descargos; y en la que la sentencia del juez -lamentablemente sólo en casos ideales- recurre a intervención contextual, en tanto elige una forma de pena que tiende a favorecer en vez de impedir la resocialización).

Frente a un proceso jurídico, los sistemas de deliberación tienen que vérselas con la dificultad decisiva de no disponer de una ley 'objetiva' que dirija la discusión. En un sistema de deliberación social, los actores se deben dirigir a sí mismos; deben ellos mismos definir las reglas de su interacción y deben, a lo menos, entenderse en la validez de esas reglas. La forma procedimental en que esto podría suceder quisiera llamarla discurso, en una referencia más bien débil a Jürgen Habermas.

En un discurso se encuentran actores, como representantes de sistemas sociales parciales, con el objetivo de entenderse sobre un problema. Un discurso es, de este modo, una forma de entendimiento libre de coacción, en tanto cada actor puede renunciar a su participación cuando vea amenazados esencialmente sus intereses sistémicos. En esos dos momentos, el objetivo de entendimiento y la ausencia de coacción, los discursos sistémicos se acercan al modelo de discurso de Habermas. 
Ahora vienen las diferencias. Ellas se remiten al hecho de que un discurso sistémico como juego mutuo de actores autónomos con lógicas operativas divergentes no se dirige en primera línea al consenso, sino al disenso. Se debe entonces diferenciar, como Habermas lo hace correctamente, en qué medida un discurso contará con consenso y en qué medida con disenso; o más precisamente: cómo un consenso fundamentado es posible sobre la base de un disenso basal.

Cada operación instructiva de un actor sobre otro presupone que los sistemas sociales complejos, a pesar de su clausura operativa, intransparencia mutua, diferencias sistémicas específicas y comunicaciones codificadas de manera diferenciada son capaces y están dispuestos a cambiar entre operaciones autorreferenciales y heterorreferenciales. Estas operaciones transferenciales (Braten 1984) constituyen el núcleo de la reflexión, pero no conducen al consenso. No se orientan al consenso, ni en el sentido de una adecuación mutua ni en el sentido de un acuerdo o de estructuras causales generales. Posibilitan nada más que un juego de intercambio conducido por la comprensión de actores autónomos, en el cual no se llega a consenso, sino a un aumento de la conectividad de nuevas informaciones. Conectividad significa que la transformación de un evento del entorno logra, en la semántica interna, que un sistema derive información de un evento externo incorporándolo a su modo de operación. 'Comprensión' indica estrictamente que un observador 'reconozca un interior' (Dilthey, cit. por Schorr en Luhmann \& Schorr 1986: 28), o, en otras palabras: que desde la observación de su modo de operación y su autodescripción, un sistema se cierre.

A diferencia de Habermas, una interpretación teórico sistémica está cerca de ver la función central de los discursos, no en la producción de consenso. La tarea de los discursos es generar información que pueda ser comprendida y conectada. La aspiración de los discursos sistémicos es por tanto mucho más humilde: se ganaría mucho si los sistemas funcionales especializados de la sociedad entendieran lo que provocan en el entorno y cómo el modo de operación de otros sistemas influye sobre ellos. Queda entonces suficiente espacio para el disenso, pero al menos sería posible un entendimiento sobre los disensos y consensos específicos. Ante el actual operar ciego de los sistemas funcionales, esto supone un progreso imposible de subvalorar.

Subyace a los discursos sistémicos, el que la intervención orientativa es exitosa sólo bajo el punto de vista y en consideración de la autonomía del sistema a influir. Tal autonomía contiene, como ya se dijo, la 
hermenéutica del modo de operación de los sistemas autorreferenciales y la hermenéutica sistémico-relativa de su construcción de mundo. Ellas establecen lo que un sistema puede aceptar como información utilizable y qué no. Esto significa, entre otras cosas, que entre los sistemas funcionalmente diferenciados no se puede llegar a un consenso fundamental en los discursos, porque no hay una verdad o una rectitud generalizada. Sólo existe la posibilidad del relacionamiento de diferentes verdades (Eichmann 1989: 148). Es importante ahora entender que, para la coordinación y la orientación, el acuerdo no es necesario; basta una selección informada (en europeo antiguo: ilustrada) de cada opción sistémico-específica que en su selectividad se remitan unas a otras.

El rendimiento más destacado del discurso sistémico se ve en que los sistemas autónomos se entreguen a una política de opciones coordinada (Willke 1983: 135ss). Con esto se quiere decir que las intervenciones se coordinan como instrumentos de influencia mutua, de modo tal que se expandan las opciones para el sistema intervenido al interior de su propia lógica de operación y en consonancia con sus propios grados de libertad. Se trata de hacer accesibles esas opciones a través de una correspondiente configuración de las condiciones contextuales que no hiera la autonomía sistémica y que provoque mínimas externalidades negativas. Esta postura muestra que la disposición de los discursos al consenso sobrecarga esas externalidades y evita que se despliegue una real potencialidad, a saber: la indicación precisa de esas diferencias que no pueden ser niveladas o sobrepasadas, pero que se ofrecen como puntos de cristalización de opciones compatibilizables. La idea de 'discursos descargados de consenso' (Eichmann 1989: 138ss) es apropiada para disolver una serie de irregularidades de las concepciones de discurso orientadas al consenso, las que siempre estuvieron ligadas a una valoración positiva del consenso -por oposición al disenso- pero que en los plexos de interacción complejos no se puede establecer.

En la praxis de las sociedades desarrolladas, los discursos sistémicos (sistemas de deliberación, acciones concertadas, consejos socioeconómicos, consejos educativos, consejos científicos, comisiones tripartitas y otros similares) se han desplegado en los puntos neurálgicos de los conflictos sociales. Entretanto aparecen sistemas discursivos también a nivel regional y comunal -por ejemplo, en el campo de la política social o de la capacitación laboral (una mirada en Glagow \& Willke 1987). Lo central es que no existe un discurso sistémico de alcance general, sino que correspondientemente con la estructura federal y 
policéntrica de las sociedades desarrolladas, hay una variedad de discursos descentrales. Más importante aún: el funcionamiento de esos discursos no depende de una idea general preconcebida de la totalidad de la sociedad, no presupone la unidad identitaria o la subjetividad de la sociedad. No hay una instancia central que pueda controlar la dirección de la orientación social. El control de la dirección de la orientación tiene lugar en el juego mutuo de los actores autónomos afectados; es por eso necesariamente descentral y basada en el proceso de reflexión y coordinación de sistemas funcionales independientes. Sólo un interés mutuo en la cooperación y la expectativa de una ganancia emergente en un juego de suma positiva pone en marcha un proceso caracterizado por las cambiantes condiciones de relación entre cooperación y conflicto (Keohane 1984), no por una suerte de resolución en un gran consenso.

Cuando Habermas (1985: 415) opone a la idea de una posible orientación de la sociedad a través de discursos sistémicos que, sin un sujeto autorreferido, algo así como un conocimiento autorreflexivo de la totalidad social, sería impensable la influencia de la sociedad sobre sí misma, desconoce que fueron las reflexiones sistémicas, de las cuales él se cuelga, las que han dado cuenta del descentramiento de las sociedades desarrolladas: "Los esbozos de totalidad policéntricos, que sobrevienen, se ofrecen intercambiablemente y se anexan unos a otros producen puntos medios competitivos. Sólo las identidades colectivas danzan por aquí y por allá en el río de interpretaciones y se adecuan mejor a la imagen de una red frágil que a la de un centro estable de autorreflexión" (Habermas 1985: 417). ¡Tal cual! Es la dialéctica de inclusión y exclusión que Parsons detalladamente había descrito, la que obliga a la teoría de la sociedad a nuevas concepciones de la orientación social y de la producción discursiva de una 'identidad racional'. Habermas es suficientemente inconsecuente para malentender la mutua influencia de sistemas autorreferenciales como forma de entendimiento intersubjetivo. Para los sistemas autónomos no hay una intersubjetividad generalizada; cada uno tiene su propia y diferente intersubjetividad en la forma de un bosquejo sistémicamente relativo del 'mundo' en el que co-reflexiona su unidad como entorno de otros sistemas. Sobre todo, no subyace al entendimiento de los sistemas parciales un télos o una tendencia a la generalización. Su centro es el procesamiento de diferencias, la generación de informaciones y una política de opciones que apunte a una conectabilidad generalizada de comunicación de disenso y consenso. 
Una aproximación teórico sistémica de las sociedades desarrolladas propone, en relación con el tratamiento de sistemas complejos, la reducción de las aspiraciones generalizadas de control, dominación, ejercicio del poder y orientación de la sociedad. A la vez, esta perspectiva deja claro que un simple 'arrégleselas usted mismo' no es suficiente. Una salida de este dilema estriba en conectar la capacidad de evolución natural con la pretensión que surge de la especificidad de los sistemas psíquicos y sociales: reforzar la capacidad de autoorganización descentral y orientarla al objetivo civilizatorio que la modernidad no ha ni con mucho alcanzado. RM

\section{REFERENCIAS}

Axelrod, R. (1984). The Evolution of Cooperation. New York: Basic Books.

Axelrod, R. \& Keohane, R. (1985). Achieving Cooperation under Anarchy: Strategies and Institutions. World Politics 38(1), 226-254.

Bobbio, N. (1984). The Future of Democracy. Telos 62, 3-16.

Braten, S. (1984). The Third Position - Beyond Artificial and Autopoietic Reduction. Kybernetes 13, 157-163.

Daedalus (1988). Journal of the American Academy of Arts and Sciences. Artificial Intelligence 117(1).

Eichmann, R. (1989). Diskurs gesellschaftlicher Teilsysteme: Zur Abstimmung von Bildungssystem und Beschäftigungssystem. Wiesbaden: Deutscher Universitätsverlag.

Etzioni, A. (1968). The Active Society. New York: The Free Press.

Foemer, U. (1981). Zum Problem der Integration komplexer Sozialsysteme: am Beispiel des Wissenschaftsrates. Berlin: Duncker \& Humblot.

Foerster, H. v. (1984). Principles of Self-Organization in a Socio-Managerial Context. En H. Ulrich \& G. Probst (Eds.), Self-Organization and Management of Social Systems (pp. 2-24). Berlin: Springer.

Forrester, J (1972). Der teuflische Regelkreis: Das Globalmodell der Menschheitskrise. Stuttgart: Deutsche Verlags-Anstalt.

Glagow, M., \& Willke, H. (1987). Dezentrale Gesellschaftssteuerung. Probleme der Integration polyzentrischer Gesellschaften. Pfaffenweiler: CentaurusVerlagsgesellschaft.

Habermas, J. (1985). Der philosophische Diskurs der Moderne. Frankfurt: Suhrkamp.

Honneth, A. (1985). Kritik der Macht. Reflexionsstufen einer kritischen Gesellschaftstheorie. Frankfurt: Suhrkamp.

Keohane, R. (1984). After Hegemony. Cooperation and Discord in the World Political Economy. Princeton NJ: Princeton University Press.

Koselleck, R. (1979). Vergangene Zukunft. Frankfurt: Suhrkamp.

Lindblom, C. (1965). The Intelligence of Democracy. New York: The Free Press.

Luhmann, N. (1975). Macht. Stuttgart: UTB.

Luhmann, N. (1984). Soziale Systeme. Grundrisse einer allgemeinen Theorie. Frankfurt: Suhrkamp. 
Luhmann, N. (1986): Ökologische Kommunikation. Opladen: VS Verlag für Sozialwissenschaften.

Luhmann, N. y Schorr, K. (Hrsg.) (1986). Zwischen Intransparenz und Verstehen. Frankfurt: Suhrkamp.

McCulloch, W. (1965). Embodiments of Mind. Cambridge Mass.: The MIT Press.

Mayntz, R. (1983). Zur Einleitung: Probleme der Theoriebildung in der Implementationsforschung. En R. Mayntz (Ed.), Implementation politischer Programme II. Ansätze zur Theoriebildung (pp. 7-24). Opladen: VS Verlag für Sozialwissenschaften.

Peat, D. (1988). Artificial Intelligence. How Machines Think. New York: Baen.

Piaget, J. (1971). Biology and Knowledge. Chicago: University of Chicago Press.

Piaget, J. (1973): Das moralische Urteil beim Kinde. Frankfurt: Suhrkamp.

Polanyi, K. (1978). The Great Transformation. Frankfurt: Suhrkamp.

Polanyi, M. (1951). The Logic of Liberty. London: Routledge.

Scharpf, F. (1985). Die Politikverflechtungs-Falle: Europäische Integration und deutscher Föderalismus im Vergleich. Politische Vierteljahresschrift 26, 323-356.

Simon, H. (1978). Die Architektur der Komplexität. En K. Türk (Ed.) Handlungssysteme (pp. 94-120). Opladen: VS Verlag für Sozialwissenschaften.

Smith, A. (1974). Entstehung und Verteilung des Sozialprodukts. München: C.H. Beck.

Stichweh, R. (1988). Inklusion in Funktionssysteme der modernen Gesellschaft. En R. Mayntz, B. Rosewitz, U. Schimank, \& R. Stichweh (Eds.), Differenzierung und Verselbstandigung. Zur Entwicklung gesellschaftlicher Teilsysteme (pp. 261-294). Frankfurt/New York: Campus Verlag GmbH.

Teubner, G. (1982). Reflexives Recht. Archiv für Rechts- und Sozialphilosophie 69, 13-59.

Teubner, G. y Willke, H. (1984). Kontext und Autonomie: Gesellschaftliche Selbststeuerung durch reflexives Recht. Zeitschrift für Rechtssoziologie 5, 4-35.

Unger, R. (1976). Law in Modern Society. Towards a Criticism of Social Theory. New York/London: The Free Press.

Weber, M. (1972). Gesammelte Aufsätze zur Religionssoziologie. Bd. 1-3. Tübingen: JCB Mohr.

Willke, H. (1983). Entzauberung des Staates. Überlegungen zu einer gesellschaftlichen Steuerungstheorie. Königstein/Ts.: Athenäum-Verlag

Willke, H. (1984). Gesellschaftssteuerung. En M. Glagow (Ed.), Gesellschaftssteuerung zwischen Korporatismus und Subsidiarität (pp. 29-53). Bielefeld: AJZ.

Willke, H. (1986a). Entzauberung des Staates. Grundlinien einer systemtheoretischen Argumentation. Jahrbuch für Verwaltungswissenschaft 1, 285-308.

Willke, H. (1986b): Three Types of Legal Structure: The Conditional, the Purposive and the Relational Program. En G. Teubner (Ed.), Dilemmas of the Law in the Welfare State (pp. 180-299). Berlin-New York: De Gruyter.

Willke, H. (1987a): Strategien der Intervention in autonome Systeme. En D. Baecker, J. Markowitz, R. Stichweh, H. Tyrell \& H. Willke (Eds.), Theorie als Passion. Niklas Luhmann zum 60. Geburtstag (pp. 333-361). Frankfurt: Suhrkamp.

Willke, H. (1987b): Kontextsteuerung und Re-Integration der Ökonomie: zum Einbau gesellschaftlicher Kriterien in ökonomische Rationalität. En M. Glagow \& H. Willke (Eds.), Dezentrale Gesellschaftssteuerung. Probleme der Integration polyzentrischer Gesellschaft (pp. 155-172). Pfaffenweiler: Centaurus- 
Verlagsgesellschaft.

Willke, H. (1988a). SDI: Die Strategische Verteidigungsinitiative - 5 Jahre danach. Zeitschrift für Politik 4, 353-364.

Willke, H. (1988b). Systemtheoretische Grundlagen des therapeutischen Eingriffs in autonome Systeme. En L. Reiter, E. Brunner, \& S. Reiter-Theil (Eds.), Von der Familientherapie zur systemischen Perspektive (pp. 41-50). Berlin: Springer.

\section{SOBRE EL AUTOR}

Helmut Willke fue desde el año 2002 Profesor de Teoría del Estado y Global Governance en la Facultad de Sociología de la Universidad de Bielefeld, Alemania. Ha sido también Profesor visitante en Washington D.C., Genf y Viena, entre otros. En 1994 obtuvo el premio Leibniz de la Comunidad de Investigación Alemana. Desde 2008 es Professor de Global Governance de la Zeppelin Universität, Alemania, y Vicepresidente de Investigación de la misma Universidad desde 2015. Sus temas centrales de trabajo en la actualidad son teoría de sistemas, teoría del Estado, regímenes de gobierno global, management del conocimiento. Entre sus publicaciones están la trilogía Atopia (2001), Heterotopia (2002), Dystopia (2003) por Suhrkamp, Symbolische Systeme (2005, Velbrück) y últimamente Regieren. Politische Steuerung komplexer Gesellschaften (2014, Springer), Demokratie in Zeiten der Konfusion (2014, Suhrkamp), entre otros.

CONTACTO

Lehrstuhl für Global Governance

Zeppelin Universität

Am Seemooser Horn 88045

Friedrichshafen, Bodensee

Deutschland

helmut.willke@zu.de

Recibido: Noviembre 2015

Aceptado: Marzo 2016 